\title{
O teatro visual como teatro performativo
}

\section{Visual theater as performative theater}

Wagner Cintra ${ }^{1}$ 


\section{Resumo}

Um dos fenômenos que marcaram o teatro no início do século XX foi a aproximação com as artes plásticas. Tal fenômeno repercute até os dias atuais por meios de inúmeras manifestações artísticas que buscam constantemente $o$ desenvolvimento de linguagens cada vez mais renovadoras. O Teatro Visual, por sua vez, surge como uma linguagem teatral marcada pelo hibridismo que atua na interface do teatro com as artes visuais e coloca em cena diversos elementos conjugados no mesmo nível de existência poética: marionetes, objetos, atores, etc. Em tal contexto, este trabalho pretende dar voz a uma linguagem teatral cujos conceitos estão em desenvolvimento, a qual ainda é um território desconhecido, sobremodo no Brasil. Este artigo apresenta uma visão geral desse universo enfatizando a presença humana em cena.

Palavras-chave: Teatro Visual; artes visuais; hibridismo

\section{Abstract}

One of the phenomena that have become apparent in the world of theater at the beginning of the 20th century was its approach to the visual arts. Such phenomenon still reverberates nowadays by innumerous artistic manifestations that are constantly seeking for the development of innovative ways of making art. Visual Theater, in turn, emerges as a new theatrical language, which is marked by the existing hybridity in the interface between theater and visual arts, and therefore, brings to the stage a series of elements that are conjured up at the same poetical level among both types of arts: puppets, objects, actors and actresses etc. In that way, this kind of work intends to give voice to a theatrical language whose concepts are under development and that are still an unknown territory, especially in Brazil. This article presents a general view about this universe emphasizing the human presence in scene.

Keywords: Visual Theater; visual Arts; hybridity 
Tratar o objeto, obra ou produto como performance significa investigar o que essa coisa faz, como interage com outros objetos e seres, e como se relaciona com outros objetos e seres. (Schechner, 2003b, p. 25)

De início, é importante assinalar que o contexto trabalhado neste artigo é fundado sobre uma experiência pessoal, sobre compêndios poéticos resultantes de uma acentuada pesquisa, teórica e prática, que vimos realizando no Instituto de Artes da Unesp, nos últimos dez anos. Devido à escassez de estudos e material bibliográfico acerca do tema, falar do Teatro Visual não é uma tarefa simples. Tendo isso em vista, para elaborar uma reflexão acerca dos princípios dessa linguagem, utilizaremos como exemplo as duas últimas produções do Teatro Didático da Unesp²: Pauliceia Desvairada, inspirado na obra homônima de Mário de Andrade, e Judas: Piedade para os Ratos, inspirada em poemas de Augusto dos Anjos.

O pensamento aqui exposto não pretende ser a expressão ou a tentativa de conceituação do Teatro Visual como linguagem. Pretendemos unicamente colocar em perspectiva alguns pontos a partir de duas experiências pessoais que possibilitem uma reflexão mais pontual acerca de uma linguagem que ainda está em desenvolvimento.

Dos muitos elementos que compõem, ou que podem compor, os domínios do Teatro Visual, a presença humana é a que possui a maior complexidade no processo de configuração estética das obras e é basicamente acerca de sua presença em cena que trataremos neste artigo. Entretanto, antes de averiguarmos as condições da existência humana nesse universo poético, será necessário primeiramente o entendimento de alguns contextos do surgimento dessa linguagem.

\section{Peculiaridades do Teatro Visual na História e as Encenações do Teatro Didá- tico da Unesp}

A aproximação do teatro com as artes visuais, sobremaneira a pintura, foi um dos fenômenos artísticos mais significativos do século XX. Esse fenômeno repercute ainda hoje por meio de inúmeras experiências artísticas que buscam ultrapassar as fronteiras do fazer teatral. Independentemente de qualquer engajamento, o teatro é uma experiência visual. Entretanto, em encenadores como Leszek Madzik, Philippe Genty, entre outros que atuam na interface do teatro com as artes visuais, a visualidade é opção de linguagem.

O Teatro Visual, como linguagem autônoma, surge como uma estrutura híbrida, ou seja, uma linguagem que atua na interface do teatro com as artes visuais, cuja origem está na Europa da década de 1980. Nesse período, a arte dramática estava em uma fase de composição aberta em que a comunicação verbal havia se enfraquecido e perdido a primazia da cena teatral. Era um momento em que as concepções realistas e psicológicas de um teatro verbal mostravam-se insuficientes para que uma experiência estética se realizasse plenamente. Em tal contexto, alguns grupos de marionetistas perceberam que a designação de teatro de marionetes já não explicava

2 Grupo de extensão universitária que, nos últimos oito anos, se dedica ao estudo do Teatro Visual. Suas produções já foram apresentadas em diversos festivais e mostras em seis estados brasileiros e em três países (México, Portugal, República Tcheca). 
o trabalho que realizavam ${ }^{3}$. As realizações desses grupos estavam muito distantes das do tradicional teatro de marionetes, principalmente pela ocorrência muito significativa da presença da figura do manipulador na cena.

De maneira geral, o Teatro Visual tem por princípio a utilização de todo e qualquer material como substância criativa, incluindo a presença humana, ativa ou não, que é colocada em cena no mesmo nível dos demais elementos. Nesse contexto, o Teatro Visual, conforme assinalou Henryk Jurkowski, tornou-se uma linguagem que "... reúne artistas vindos de todos os horizontes, que se expressam cada um na sua linguagem" (Jurkowski, 2008, p. 168), artistas nativos não somente do teatro de animação, mas também das artes visuais e do teatro tradicional de atores. Nessa circunstância, é evidente que o material humano, quando colocado em cena, posto em jogo com marionetes, objetos, máscaras, formas diversas, entre outros, não cria uma experiência representacional, mas uma experiência real em que o próprio manipulador, em se tratando da especificidade do teatro de animação, passa a ser entendido como matéria do processo de construção visual do espetáculo. Nesse contexto, a presença humana em cena, entendida como realidade material, sempre conceberá o Teatro Visual como uma linguagem muito próxima da performance.

Em tal contextura, as encenações realizadas pelo Teatro Didático da Unesp aproveitaram-se das obras dos dois poetas brasileiros para examinar e inferir alguns intentos do Teatro Visual por meio de criações cênicas. Os espetáculos encenados não ilustram as obras nem de Mário de Andrade (1893 - 1945), nem de Augusto dos Anjos (1884 - 1914); as encenações são criações autônomas que no máximo estabelecem com elas um diálogo de segundo grau ${ }^{4}$ no sentido da assimilação do conteúdo de imagens que são retrabalhadas na forma de códigos teatrais. As imagens intuídas das obras literárias, veementes de significados, transformaram-se em alegorias de estados de existências do homem ${ }^{5}$ diante de realidades peculiares da vida.

Na encenação de Pauliceia Desvairada (2017) ${ }^{6}$, a cidade de São Paulo, a quarta maior cidade do mundo, não está em cena como cenário, mas como protagonista invisível que se revela, sobretudo, por meio das suas contradições espaciais e pela matéria que compõe o seu gigantismo: aço, concreto, pessoas, animais, etc. A relação visceral que o autor tinha com a cidade em meados dos anos 1920, uma cidade em transformação contínua, que se refazia e se refaz incessantemente a cada instante, dita o ritmo da obra que é considerada a primeira obra de vanguarda do modernismo brasileiro. Da mesma maneira que Pauliceia Desvairada rompeu bravamente com a

\footnotetext{
3 Segundo Henryk Jurkowski, o termo Teatro Visual foi criado por Hadas Ophrat, diretor do The Train Theater, em Jerusalém, em 1980 (Jurkowski, 2008 , p. 168). Hadas Ophrat (1956), artista plástico, performer, escultor e marionetista israelense, foi o responsável pela formação de toda uma geração de marionetistas profissionais em Israel, tanto na Escola de Teatro Visual de Jerusalém quanto no Departamento de Teatro da Universidade de Tel-Aviv. Em 1986, Ophrat funda, em Jeruzalém, o The Scool of Visual Theatre. Ambicionando uma formação multidisciplinar, a Escola de Teatro Visual de Jerusalém assegura a formação de profissionais em todas as disciplinas das artes visuais. Sua pedagogia é fundada no pluralismo da interdisciplinaridade promovendo a abertura para todas as artes do espetáculo e inter-relacionando o teatro de atores, cenografia, teatro de marionetes, teatro de objetos, dança, vídeo, entre outros
}

4 De "segundo grau", pois alude a uma realidade escondida e subjetiva, e não a uma realidade aparente e concreta. Maurice Maeterlinck chama de diálogos "úteis" ou externos (primeiro grau) aqueles que acompanham e explicam as ações em contraponto ao "diálogo inútil" ou de "segundo grau" que fala diretamente às almas (Maeterlinck, 1986).

5 Referindo-me ao gênero humano.

6 As produções do Teatro Didático da Unesp, de maneira geral, são realizadas em três anos e em três fases. A pesquisa desenvolvida no período tinha por tema Teatro Visual - da matéria à forma. O primeiro ano de Pauliceia Desvairada, 2014/15, foi dedicado ao estudo da matéria; 2016, ao estudo da forma, e, 2017, à organização da dramaturgia. Cada fase, quando concluída, foi compartilhada com os espectadores na forma de exercícios espetáculos. 
estética literária vigente, a encenação realizada pelo Teatro Didático da Unesp rompe com paradigmas do teatro representacional. A cidade de São Paulo, a Pauliceia Desvairada, de Mário de Andrade, pode ser lida como um inventário das vivências, percepções e sensações desencadeadas pela modernização em que o autor mostra, ao longo da obra, uma relação ambígua com a cidade, que ora é tumba de homens massacrados pelos ventos da ambição, ora é palco de multicoloridos festejos. Entretanto, no que se refere à obra teatral, somente por meio do jogo com a matéria bruta $^{7}$ - metal, plástico, papel amassado, etc. - - a encenação oferece ao espectador possibilidades infinitas de entendimento por meio de múltiplas relações simbólicas. Essas relações simbólicas e qualquer possivel entendimento pertencem unicamente ao espectador, já que, no espetáculo, do ponto de vista do conteúdo, não existe nada para ser comunicado.

A encenação de Judas: Piedade para os Ratos $(2016)^{8}$, por sua vez, não foi inicialmente inspirada em uma obra literária, e sim em um tema, uma abstração. Não nos interessava contar a história de Judas Iscariotes, talvez a figura mais controversa de todos os tempos no universo cultural judaico-cristão, e como sua atitude foi decisiva na prisão, julgamento e morte de Jesus. O questionável discípulo tornou-se símbolo da incompreensão da mensagem e da traição dos princípios espirituais do seu mestre - a imagem de Judas tornou-se metáfora histórica de deslealdade e traição. Todavia, com o trabalho em desenvolvimento, a encenação de Judas: Piedade para os Ratos encontrou na poesia do poeta paraibano Augusto dos Anjos inspiração para refletir cenicamente a presença humana no Teatro Visual com base no singular tema da ingratidão.

\footnotetext{
7 Os artistas do Teatro Visual utilizam-se de todo material disponível para a construção da visualidade dos espetáculos. Entretanto, a opção do Teatro Didático da Unesp foi pela utilização da matéria bruta. Ou seja: todo o material utilizado é trabalhado na sua condição de matéria bruta, preferencialmente a mais simples. Para nós, tudo o que está em cena é entendido como matéria. Essa nossa opção pela matéria bruta decorre principalmente da concepção kantoriana de "Realidade de classe baixa", que busca elevar à categoria de Obra de Arte objetos e materiais descartados pela sociedade de consumo, principalmente aqueles destinados às latas de lixo. Tadeusz Kantor atribuía ao artista polonês Bruno Schulz (1892 - 1942), ainda hoje pouco conhecido fora da Polônia, mas considerado pela crítica como um dos mais extraordinários escritores do século XX, um dos criadores da "Realidade degradada", que se tornaria o centro da própria obra. Por esse caminho, podemos entender o Teatro Visual, na concepção por nós desenvolvida com o Teatro Didático da Unesp, também como Teatro da Matéria.
}

8 Ao contrário das demais produções do Teatro Didático da Unesp, Judas: Piedade para os Ratos foi montada em seis meses como um artifício de estudo e entendimento do Teatro Visual como Teatro Performativo. Esse espetáculo, em 2017, levou, pela segunda vez, o grupo ao México, para participar do festival internacional organizado anualmente pela UNAM (Universidade Nacional Autônoma do México), como convidado. 


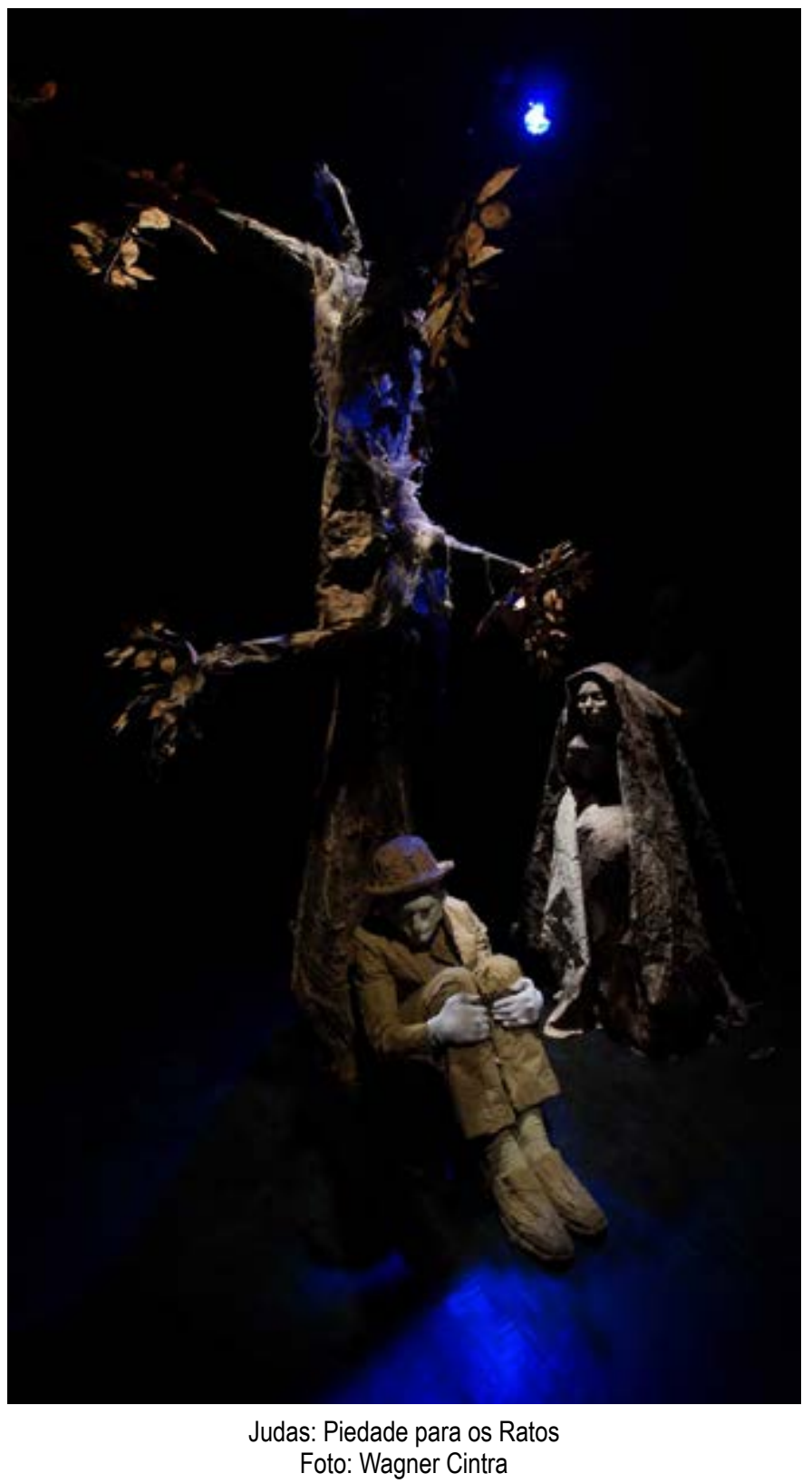

Assim como em Pauliceia Desvairada, a encenação de Judas - Piedade para os Ratos não conta a história do discípulo de Jesus. Judas não está em cena. Ele é apenas intuído por meio das diversas situações que aludem a estados de comportamentos limite. Em cena, observa-se somente um insistente movimentar de seres incógnitos e inominados. As imagens intuídas do mito cristão converteram-se em alegorias da condição do homem ante uma realidade pautada pela decepção com as relações humanas. Entretanto, apesar de todo o pessimismo, sobremodo o de Augusto dos Anjos, que maravilhosamente contaminou todo o jogo cênico, evocado pelas imagens, ainda resta um fio de esperança, uma possível Piedade ${ }^{9}$ como redentora de todas as mazelas deste mundo.

\footnotetext{
9 Inicialmente essa figura era uma marionete em tamanho real manipulada por um único manipulador; posteriormente se tornou máscara: uma figura de mulher envolta em papel Kraft, cuja única função é olhar a cena. A associação à Pietá de Michelangelo se deu a posteriori como interpretação dos espectadores, e não como personagem preconcebida.
} 
Entretanto, apesar de a ingratidão ser uma temática insistente e presente, não nos interessava teatralizar os poemas, pelo contrário: interessava-nos o conteúdo ulterior da obra de Augusto dos Anjos, pois nos possibilitava um mergulho na abstração, ao associarmos o enunciado dos poemas às matérias trabalhadas em cena. Com essa simbiose, a obra literária também passa a ser entendida como matéria plástica e também sonora, associada e integrada ao conteúdo da sonoplastia. Em resumo, a literatura só passa a ter valor no Teatro Visual quando vinculada à realidade das matérias constituintes dos espetáculos. Acerca da ausência de texto no espetáculo Judas - piedade para os ratos, Jorge Dubatti ${ }^{10}$ diz:

[...] me pareceu um espetáculo na linha simbolista que muito lembra a vanguarda histórica do surrealismo, e também ao surrealismo de grandes mestres da pós-vanguardas do século XX, como Tadeusz Kantor e Philiipe Genty [...]. Me interessou muito esse espetáculo que eu chamaria de um Teatro Hieroglífico, ou seja: um teatro cujos signos não podemos identificar claramente e que se organiza em uma estrutura simbólica, [...]. O espectador sente que está diante de uma linguagem que não conhece, e, portanto, é obrigado a fazer um esforço para se conectar com o outro, com algo que não é do seu cotidiano. Assim, o Teatro Hieroglífico seria o contrário de um teatro tautológico em que se busca algo conhecido. Vale apenas lembrar que hieroglífico significa "a escritura do sagrado" [...], busca do sagrado como dizia Antonin Artaud. Nesse sentido, o espetáculo trabalha com uma quantidade de questões muito interessantes, como o silêncio por exemplo. O espetáculo está baseado em uma série de poemas de um autor chamado Augusto dos Anjos - há textos, mas são muito breves. Noventa por cento do espetáculo está centrado no que chamaríamos de silêncio. E o silêncio está muito relacionado com a ideia de sagrado e de simbolismo. Eu recordaria o grande mestre do simbolismo, Maurice Maeterlinck, que tem um artigo chamado O Silêncio, no qual ele fala de um silêncio ativo e de um silêncio passivo. $\mathrm{O}$ silêncio passivo é um silêncio do nada, já o silêncio ativo é um silêncio da presença. O mais interessante de se trabalhar com o silêncio no teatro, neste tipo de Teatro Hieroglífico, é a ideia de regresso à infância, à ideia de infans; que não fala. É necessário entender que no Teatro Hieroglífico há linguagem, porém não há linguagem verbal. E isso recoloca o espectador em um lugar sensível que não passa pela racionalidade ${ }^{11}$.

10 Jorge Dubatti (1963 -) é professor de História do Teatro Universal na Faculdade de Filosofia e Letras da Universidade de Buenos Aires - Argentina. É um dos mais importantes nomes da crítica e da historiografia teatral da atualidade.

11 Depoimento de Jorge Dubatti após a apresentação do espetáculo Judas - piedade para os ratos, no XXIV FITO (Festival Internacional de Teatro Universitário), realizado de 11 a 19 de fevereiro de 2017 na Cidade do México. www.facebook.com/Teatro-Didático-da-UNESP-279906568800150/?ref=tn_tnmn 


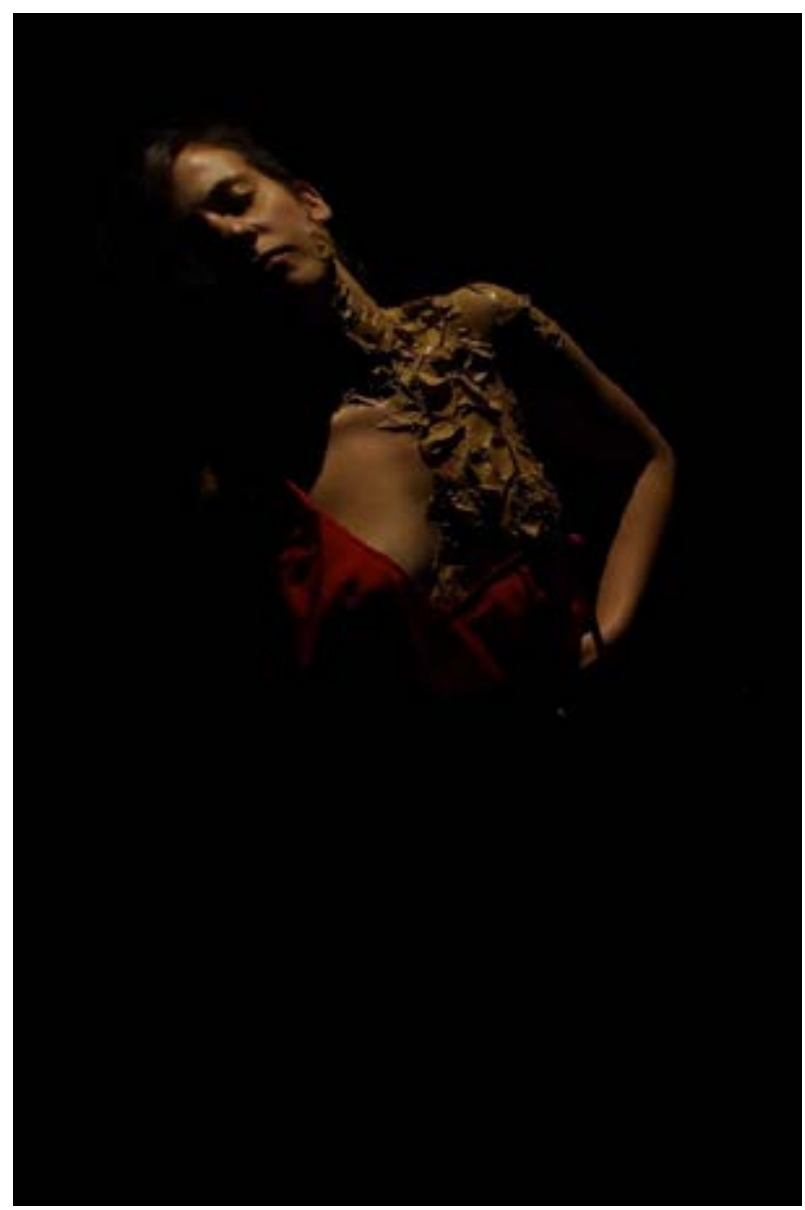

Judas: piedade para os Ratos.

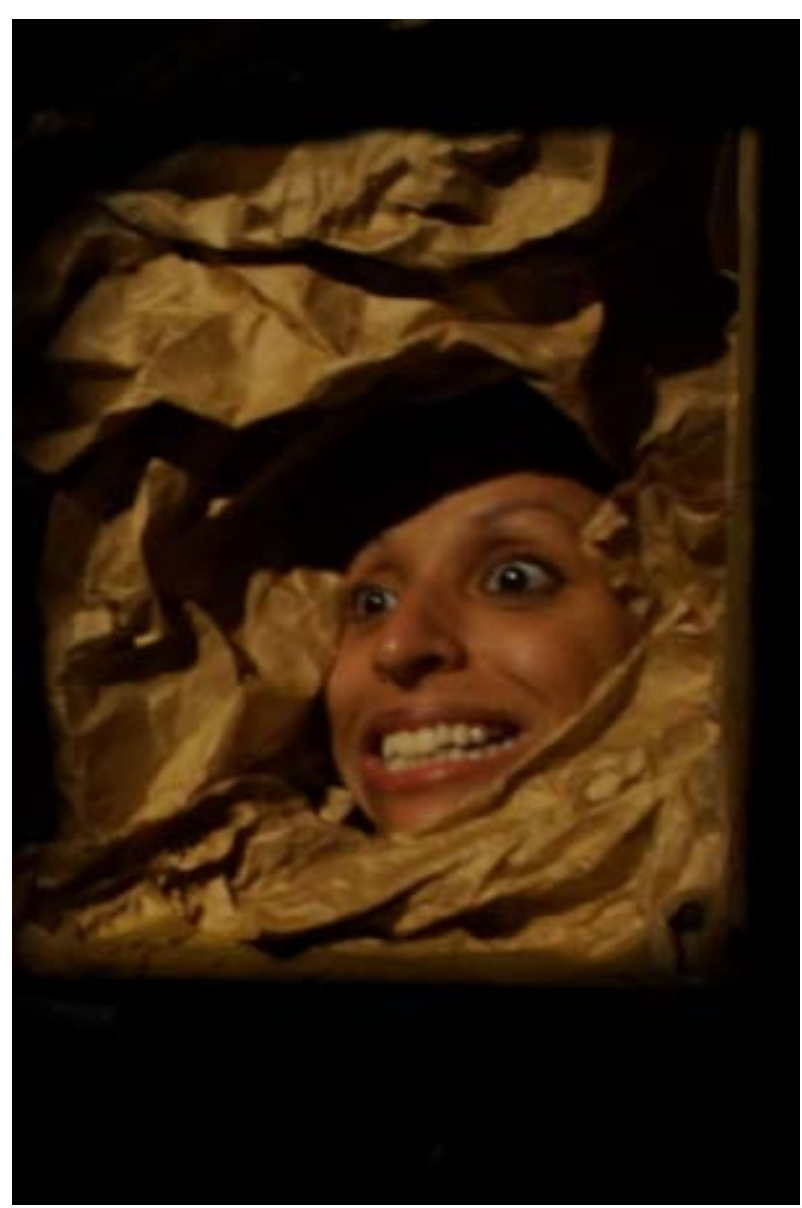

Paulicéia Desvairada

Fotos: Wagner Cintra

Tanto Pauliceia Desvairada como Judas: Piedade para os Ratos são realidades plásticas que existem unicamente em relação a sua forma. A presença humana em ambos espetáculos, "coisificada", mistura-se à matéria inerte, sobremodo o papel Kraft amassado, que é a matéria básica da construção visual dos espetáculos e envolve a matéria humana viva, revelando-se, na sua simplicidade, mais poderosa que a pele do ator.

Outro aspecto essencial do Teatro Visual, já indicado anteriormente, é a dimensão não representacional dos espetáculos. O que está em cena são abstrações; são materialidades contraditórias por sua forma, e não por seu conteúdo. Nos espetáculos, não há nada para ser representado. As imagens são o que, de fato, são e não pretendem ser nada mais do que imagens. ${ }^{12}$ A sua existência está assegurada pelos jogos com seu tamanho, textura, lugar no espaço, etc. No contexto da forma, o Teatro Visual respalda-se essencialmente nos vínculos que se criam em cena entre diferentes matérias, inclusa a matéria humana. Esses vínculos constroem um complexo jogo simbólico, já que todo e qualquer elemento colocado em cena, mesmo que ao acaso, sempre será signo de alguma coisa. No entanto, esse jogo simbólico e qualquer possível entendimento pertencem somente ao espectador, tendo em conta que nos espetáculos, do ponto de vista do conteúdo, não existe nada para ser comunicado. Pauliceia Desvairada e Judas: Piedade para os Ratos são mormente poesias da matéria, encantos para o olhar.

12 A imagem no Teatro Visual é uma imagem real, e não imitativa. Ou seja: a sua percepção não depende de nenhum artifício da imaginação do espectador no sentido de um teatro de ilusão. 


\section{A performatividade no Teatro Visual}

Existe algo no Teatro Visual que não pode ser tocado, interpretado racionalmente, mas apenas intuído. As relações entre as formas, particularmente aquelas que ocorrem entre o inanimado e o humano, entre o abstrato e o concreto, destroem as convenções naturalistas e psicologizantes do teatro, chocando-se sistematicamente contra a convenção de um teatro de ilusão. As formas nesse teatro (referindo-me à concepção do Teatro Didático da Unesp) são o que são. Elas, de fato, existem e não "presentificam" uma realidade ausente que poderia ser chamada de representação. As formas nesse teatro têm uma existência autônoma e real. Todo objeto colocado em cena existe em si e nada está no lugar de outra coisa, como acontece no processo tradicional de imitação no teatro. Sendo assim, a presença humana em cena também é coisa, é objeto, é matéria.

Ao considerarmos a presença humana como matéria, devemos equalizá-la no mesmo "volume" dos demais elementos que povoam o espaço cênico. Isso sendo feito, incorremos no seguinte caso: se o corpo humano é objeto, se é somente matéria, é preciso considerar que ao humano no Teatro Visual não se atribui nenhum valor representacional, já que a nenhum outro elemento esse valor é atribuído. Ou seja: as formas geométricas no início e fim de Pauliceia Desvairada existem na sua condição de figuras geométricas. Qualquer interpretação simbólica da sua existência na cena acontecerá a posteriori e caberá unicamente ao espectador. Esses objetos existem unicamente por sua forma, movimento e matéria.

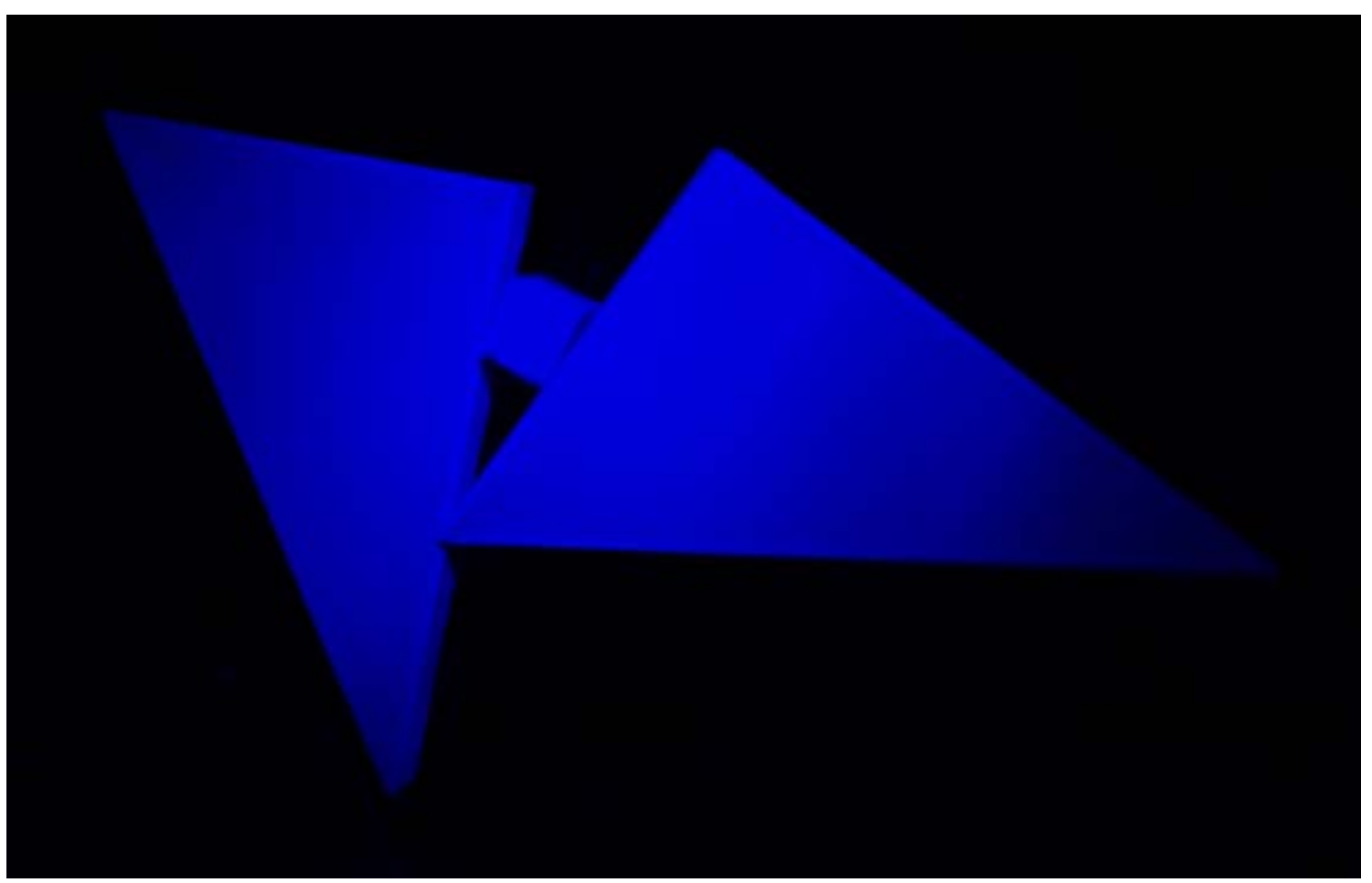

Paulicéia Desvairada - Foto: Wagner Cintra

O mesmo acontece com as marionetes. As marionetes utilizadas nos espetáculos são singulares, pois são feitas de jornal velho amassado e modelado com fita crepe, 
branca ou marrom ${ }^{13}$. A marionete possui uma peculiaridade, que é a sua existência como personagem. A marionete não representa; ela é personagem. Quando pensamos o tradicional processo de entendimento da representação no teatro, consideramos que representar seria "tornar presente alguma coisa ausente". Ou seja: quando um ator representa Hamlet, ele torna presente, por meio do seu corpo, da sua imagem, a personagem que está ausente. Nesse contexto, representar é "presentificar", tornar concreta uma ideia, uma existência abstrata. Isso não acontece com a marionete, pois, como personagem, a sua existência está assegurada na sua condição de objeto/ imagem real. Sendo assim, a marionete existe em cena como objeto real da mesma maneira que as formas geométricas existem, antes de qualquer proposição simbólica, como objetos reais. Logo, a presença humana como imagem também deverá existir na sua condição de objeto real. Se um objeto no Teatro Visual existe como fundamento da matéria bruta que o compõe, sendo a sua imagem resultante dessa matéria, havemos de concluir que a existência humana, na contextura de espetáculos de Teatro Visual, também são materialidades em que o corpo humano como objeto visual se traduz em uma prerrogativa material para a visualidade.

A representação teatral é uma construção da consciência e a consciência é uma prerrogativa dos seres humanos. É exatamente por isso que não existe representação no universo do inanimado. Os objetos e marionetes desconhecem a consciência e, assim, não podem representar limitando-se à sua existência real. Em Judas: Piedade para os Ratos, o boneco na cadeira de rodas é um boneco na cadeira de rodas e sua existência se limita a essa condição visual que o determina como tal, ou melhor, como personagem real. Real porque ele existe, insisto, na sua condição de imagem e esta imagem só é possível por meio da matéria que o compõe. No caso, jornal velho e fita crepe.

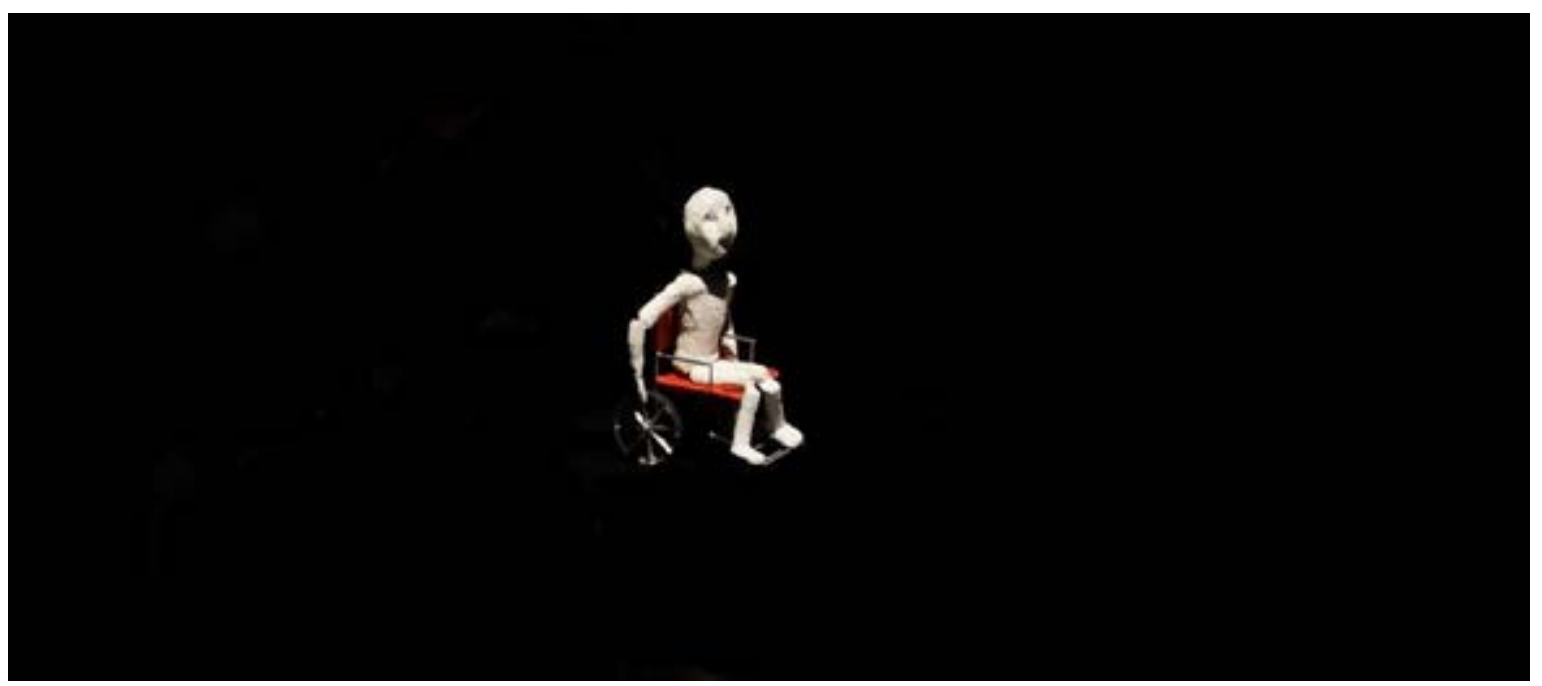

Judas: Piedade para os Ratos - Foto: Wagner Cintra

Os cubos flutuantes de Pauliceia Desvairada, por sua vez, não são apenas cubos, são objetos cuja matéria base de sua feitura é o papel Kraft amassado. Se, por um lado, a forma volumétrica retangular desses objetos faz eclodir um contexto abstrato

13 A opção por esse tipo de confecção de marionetes articuladas decorre, mais uma vez, do nosso entendimento da concepção kantoriana de "Realidade de classe baixa". 
e, por consequência, simbólico no entendimento do espectador, a sua aparência, por outro, amplia significativamente as possibilidades de significação, já que, mais do que geometria, esses cubos são objetos com texturas, as quais são espécies de leitmotivs visuais que nos permitem falar de certa Dramaturgia da Visualidade ${ }^{14}$, em que uma narrativa visual se constitui por meio de relações plásticas intrínsecas entre os objetos e as formas presentes no espaço.

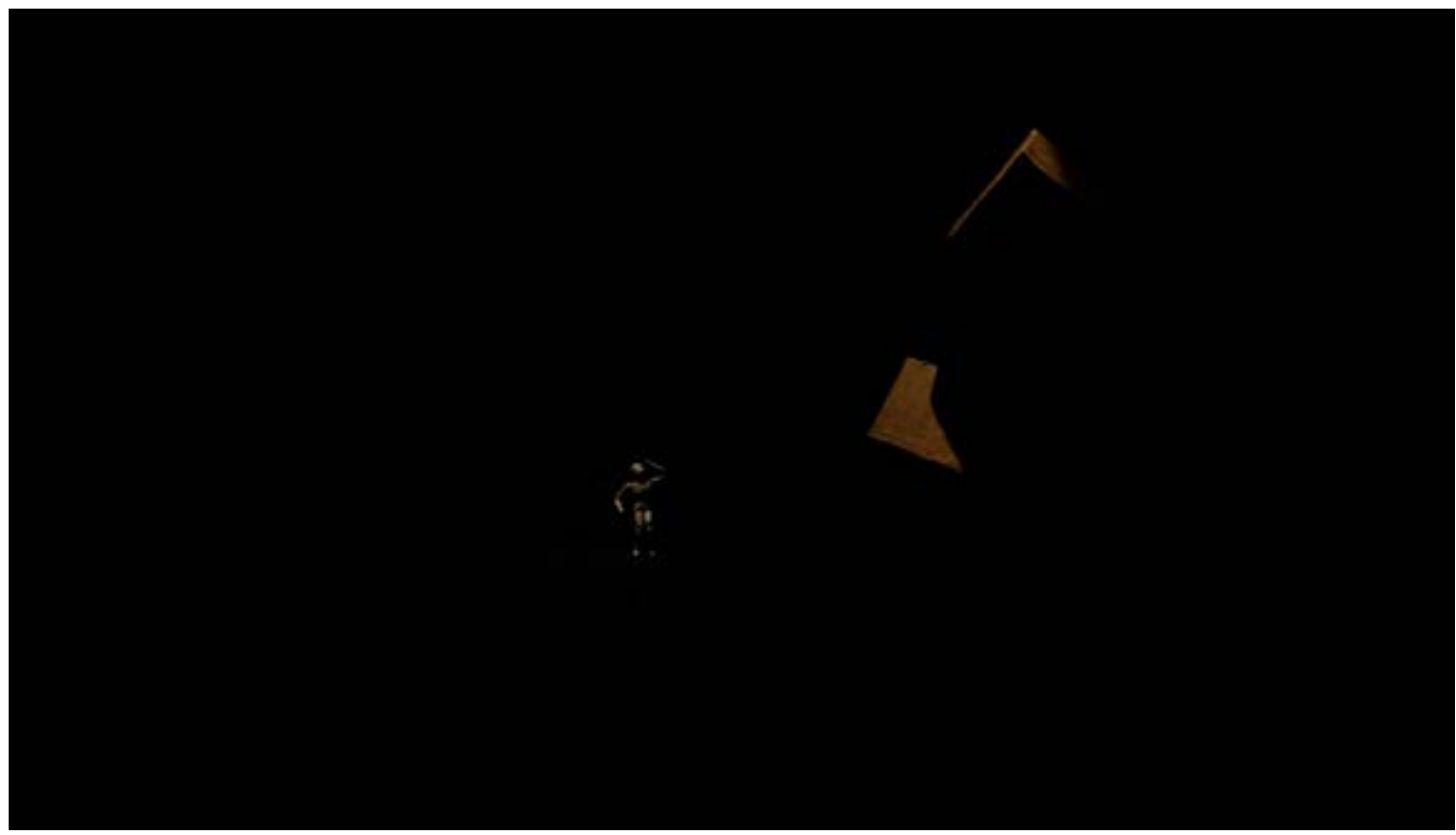

Paulicéia Desvairada - Foto: Wagner Cintra

Em se tratando de relações plásticas em cena, como exemplo, além do trabalho por nós realizado no Instituto de Artes da Unesp, essas podem ser observadas no teatro de Leszek Madzik, pelo menos no seu teatro até meados dos anos 2000. Madzik, artista plástico de formação, colocou-se na direção da criação de obras plásticas, a maioria de conteúdo aberto ao entendimento do espectador. De acordo com o comentário de Jurkowski (2008, p. 174):

[...] ele iniciou a sua carreira como cenógrafo. Os cenários, concebidos como espaços plásticos, serviam de ponto de partida para imagens sugestivas, que se formavam como uma ordem temática e atingiam um alto grau de abstração. Ele renuncia totalmente aos atores tradicionais. Se existe a presença do ser humano, essa é utilizada mais como imagem do que como personagem. Essas pinturas constituem seu principal meio de expressão. Elas se consistem, com grande precisão, de pessoas, manequins, figuras, marionetes, e de todas as espécies de materiais que os membros do grupo, ocultos nos bastidores, manipulam com muita habilidade.

\footnotetext{
14 A Dramaturgia da Visualidade é um conceito proposto por nós, cujos componentes são estes: dramaturgia do espaço; dramaturgia da matéria; dramaturgia das formas. Informações mais detalhadas acerca do assunto podem ser encontradas no artigo O Teatro Visual e a Dramaturgia da Visualidade, publicada na Móin-Móin - Revista de Estudos Sobre Teatro de Formas Animadas, n. 12.
} 
Como é possível perceber nas palavras de Jurkowski, já no teatro de Leszek Madzik e seu Scena Plastezcna KUL ${ }^{15}$, a presença humana em cena também é utilizada, se não como matéria, como é caso do Teatro Didático da Unesp, mas fundamentalmente como elemento visual. Entretanto, essa visualidade somente se faz presente por meio do corpo humano e seus atributos.

Segundo Josette Féral, o teatro se beneficiou das descobertas da performance, principalmente no que se refere à

[...] transformação do ator em performer, descrição dos acontecimentos da ação cênica em detrimento da representação ou de um jogo de ilusão, espetáculo centrado na imagem e na ação e não mais sobre o texto, apelo à uma receptividade do espectador de natureza essencialmente especular. (Féral, 2015, p. 114).

Conforme as considerações de Féral, com a adoção de modelos oriundos dos experimentos da performance pelo teatro, as formas teatrais tradicionais fundadas na representação e identificação foram abaladas. Para esse teatro Performativo (idem, p. 113), nome que Féral julga mais adequado do que o termo teatro Pós-Dramático, definido por Hans-Thies Lehmann, a cena torna-se o império do jogo no sentido de ludens, e não mais o de representacional. A figura humana, no exercício pleno de sua humanidade em cena, substitui o modelo tradicional do ator caracterizador de personagens. Ou seja: o humano na cena "performa" e a mimesis é abolida. Nesse contexto, o teatro, ou melhor, o acontecimento cênico, torna-se uma experiência real tanto para o performer quanto para o espectador.

\footnotetext{
15 Leszek Madzik (1945 - ), fundador do Scena Plastyczna KUL em 1970, como jovem pintor, passou a se dedicar ao teatro por entender, entre outras coisas, que uma tela é insuficiente para obter do espectador a mesma intensidade de reações, sentimentos e emoções, a qual é capaz de produzir um espetáculo realizado ao vivo diante de um espectador. Madzik utiliza-se de bonecos, objetos, além da presença silenciosa do ator, que é utilizado como mais um elemento na criação das imagens. Ele abandona a palavra e apega-se à imagem, que é fortemente amparada pela exploração da luz no espaço. O Scena Plastyczna (Cena Plástica) é subsidiado pela Katolockiego Uniwersytu Lubelskiego (Universidade Católica de Lublin) inicialmente restringia suas apresentações aos palcos da universidade, mas logo buscou outras plateias e alcançou renome e atuação internacional.
} 


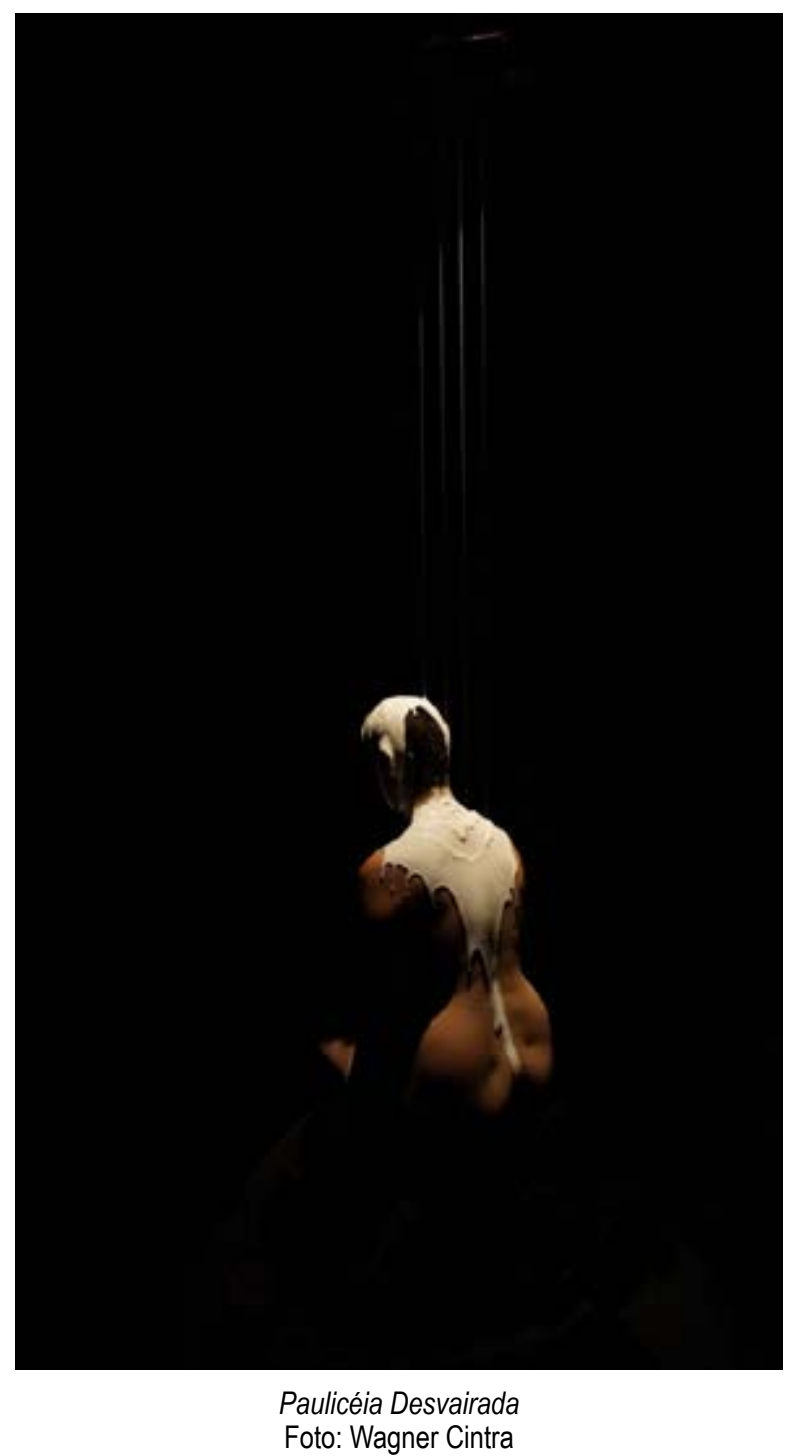

Por esse caminho, o corpo humano no Teatro Visual está livre da representação, já que é entendido somente como recurso material para a visualidade, seja como objeto visual, no caso de Leszek Madzik, seja como matéria bruta, no caso do Teatro Didático da Unesp. Ao humano não é atribuído nenhum valor além da condição de sua existência como elemento plástico. Nesse ínterim, o teatro visual se distancia da performance no sentido de que a experiência para o "performer visual", talvez o termo mais adequado na ausência de outro, apesar de ser real, é uma realidade plástica: uma experiência plástica de contato do corpo humano com outras matérias expressivas promovendo uma experiência visual única. É exatamente essa inter-relação que liga o corpo do "performer visual" a objetos, máscaras e matérias diversas, que é fundamental para o Teatro Visual.

Em uma relação de similitude, o "performer visual" em espetáculos de Teatro Visual e o performer em ação em espetáculos performativos não objetivam a construção de signos e significados. Se, no teatro performativo, aquilo que o espectador vê está além da aparência por ser uma arte da esquiva, no Teatro Visual, a significação é, antes de tudo, o próprio conteúdo plástico. Um líquido branco que escorre pelo corpo nu da "performer visual" em Pauliceia Desvairada não é nada além de um 
líquido branco escorrendo pelo corpo nu. É evidente que essa inter-relação estimula leituras simbólicas no observador. Entretanto, essas leituras são produtos da experiência cultural de cada espectador individualmente. $E$, à medida que as imagens se desenvolvem, principalmente ante a presença humana, essa instaura a ambiguidade em possíveis significações. Talvez seja essa a maior relevância da sua ocorrência em cena, ou seja: o humano no Teatro Visual promove uma alteração dos códigos e um arredamento dos sentidos. O jogo entre o humano e o inanimado no Teatro Visual é ulterior ao significado.

Para Richard Schechner, "... as obras performativas não são verdadeiras nem falsas. Elas simplesmente sobrevêm" (apud Ferál, 2015, p. 21). Da mesma maneira, o sentido no Teatro Visual, do ponto de vista da comunicação simbólica, existe na pluralidade do entendimento de cada espectador individualmente. O conteúdo, para além das relações plásticas, de maneira idiossincrática, cabe unicamente ao espectador na medida das suas vivências simbólicas e abstratas. De certa forma, 0 espectador também "performa", já que é dado a ele a liberdade de construção da própria narrativa. Como o Teatro Visual e o Teatro Performativo estão para além das formas tradicionais de teatro, os espetáculos apenas acontecem.

No Teatro Visual, especificamente, o performativo ocorre por meio de um diálogo entre todos os elementos que estão em cena e tocam na densidade das matérias que os compõem, considerando necessariamente a presença humana em cena. Assim, independentemente de todas as aproximações e divergências, o Teatro Visual só pode ser entendido como Teatro Performativo por meio do "performer visual", que é quem promove a desestabilização da realidade mediante a própria existência real na arte. Ao desconstruir a realidade, o "performer visual" leva o espectador a se mover constantemente de uma referência a outra, persuadindo o olhar a se adaptar, constante e incessantemente, de um sistema de entendimento do acontecimento teatral singular e concreto a outro plural, essencialmente abstrato e subjetivo.

Em síntese, nos espetáculos de Teatro Visual, sobremodo os encenados pelo Teatro Didático da Unesp, cada elemento, por sua forma e material com o qual é feito, é uma realidade real, e não imitativa. No espaço teatral, todo objeto traz em si uma dinâmica que a ele é própria e o difere conforme a natureza do seu material. Dessa maneira, o fascínio pela forma se impõe e se desenvolve como característica marcante do grupo, cuja pesquisa, em busca de novas possibilidades, explora a matéria no limite do seu potencial expressivo. Em cena, o humano se coisifica ao passo que matéria age e se confunde com o humano.

Desse conjunto de relações que se ampliam tenazmente, cria-se um ambiente em que não existem mais sujeitos nem objetos, mas a síntese absoluta de uma obra de arte única. Em tal contexto, o teatro Visual configura-se como uma obra artística em que o jogo estético é ponto fundamental; uma obra em que o conflito é substituído por um jogo de tensões entre o espaço, a matéria e as formas, "conteúdos básicos da Dramaturgia da Visualidade" (Móin-Móin, 2014, p. 100); uma obra em que todo componente, na cena, contribui com igual e imprescindível presença material. Nesse ambiente, o humano, aqui chamado por nós de "performer visual", que nunca está em cena sem algum outro elemento plástico a ele associado, possibilita transcendências ausentes na vida do espectador e, de certa forma, na do homem moderno 
por meio de conteúdos poéticos intensos e singulares. Assim, a matéria, como tal, faz-nos transcender a nossa própria realidade física e cotidiana, criando sugestões poéticas afastadas de nossa realidade consciente.

Desse modo, a consciência articulada apreende os elementos visuais em suas propriedades mais abstratas não delimitando a identificação dos objetos com base em identidades culturais, mas tornando-os irreconhecíveis. É uma experiência que está além do ritual e da história, pois é pura subjetividade, mas que permanece no campo do real por ser uma experiência cênica não imitativa. E assim, rescindida a convenção histórica de um teatro fundado no conflito e na identificação, a imaginação do espectador liberta das amarras do dramático, está livre para jogar com a matéria bruta e, sem impedimento, deixar-se absorver por uma linguagem que pode ser compreendida para além das barreiras culturais e linguísticas.

O Teatro Visual é poesia da visão que nos arrebata para o interior de uma "tela em movimento" por meio das revoluções e transformações da matéria que destitui o pensamento racional e nos faz transcender a nossa realidade material, proporcionando ao espectador uma vivência estética profunda, uma intensa experiência afetiva próxima do "sagrado".

\section{Referências}

ANDRADE, Mário. Pauliceia Desvairada. São Paulo: EDUSP, 2010.

ANJOS, Augusto dos. Eu e outras poesias. 42. ed. Rio de Janeiro: Civilização Brasileira, 1998.

CINTRA, Wagner. Considerações acerca do teatro visual e da dramaturgia da visualidade. In: MÓIN-MÓIN - Revista de Estudos sobre Teatro De Formas Animadas. Jaraguá do Sul: Udesc/SCAR, ano 10, Número 12 - 2014.

FÉRAL, Josette. Além dos Limites: teoria e prática do teatro. São Paulo: Perspectiva, 2015.

JURKOWSKI, Henryk. Métamorphoses - La marionnette au XXe. Siècle. Charleville-Mezières: L`Entretemps, second édition, 2008.

MAETRRLINCK, Maurice. Le tragique quotidien, in. Le trésor des humbles. Bruxelas: Labor, 1986.

SCHECHNER, Richard. O que é performance? In: LIGIERO, Zeca (Org.). Percevejo. Revista de Teatro, Crítica e Estética. Rio de Janeiro: NEPPA/Unirio, Ano 11, no 12 2003b, p. 25-50. 